\title{
Histochemical demonstration of five enzymes' activities in Macrogyrodactylus clarii (Monogenea: Gyrodactylidae) from the catfish Clarias gariepinus
}

\author{
Safaa Zaky Arafa, El-Sayed Kasem Abd El-Hady and Samir Ahmed El-Abbassy
}

Zoology Department, Faculty of Science, Mansoura University, Mansoura, Egypt

\begin{abstract}
Histochemical techniques were applied to whole mounts, to study the distribution of the enzymes alkaline phosphatase, acid phosphatase, adenosine triphosphatase, 5'-nucleotidase and glucose-6-phosphatase in the organs and tissues of a viviparous monogenean, Macrogyrodactylus clarii Gussev, 1961, from the gills of the North African catfish Clarias gariepinus (Burchell) in Egypt. The following organs and tissues were studied: head region, anterior adhesive glands, mouth region, pharynx, intestine, testis, vesicula seminalis, male accessory gland, male accessory reservoir, copulatory organ, receptaculum seminis, egg-cell forming region, embryonic cells, excretory system, nerve cells, haptor, muscle fibres and subtegumental cell bodies (cytons). The enzymes showed marked differences in their activities among the studied organs and tissues. Alkaline phosphatase and acid phosphatase activities were detected in many organs and tissues, while the activities of adenosine triphosphatase, 5'-nucleotidase and glucose6-phosphatase were restricted to a few organs. Although no positive reaction for any enzyme was observed in the anterior adhesive gland cells, a positive reaction for acid phosphatase was detected in the anterior adhesive areas. All enzymes showed marked activity in the digestive and excretory systems. The distribution of the enzymes in the tissues and organs of M. clarii is compared with those of other monogeneans, including other gyrodactylids parasitizing the same host fish. Some possible functions of the enzymes are discussed.
\end{abstract}

Keywords: Macrogyrodactylus clarii, Clarias gariepinus, histochemistry, alkaline phosphatase, acid phosphatase, adenosine triphosphatase, 5'-nucleotidase, glucose-6-phosphatase

The monogenean Macrogyrodactylus clarii Gussev, 1961 was recorded and described for the first time from the gills of the North African catfish Clarias gariepinus (Burchell) (syn. Clarias lazera) in Egypt by El-Naggar and Serag (1987). Since that date the biology of this parasite has been widely studied (see for example, El-Naggar 1993, Hagras et al. 1999, El-Abbassy 2001, El-Naggar et al. 2001a, b, 2004, El-Naggar and Cable 2007, Arafa et al. 2009). Like other gyrodactylids, M. clarii is a viviparous monogenean; its uterus may contain up to four developing embryos one inside the other. Cholinesterase activity has been demonstrated as indirect evidence of the presence of acetylcholine in the nervous system of other monogeneans (see for example, Halton and Jennings 1964, Halton and Moris 1969, Rahemo and Gorgees 1987, Buchmann and Mellergaard 1988, Cable et al. 1996, Zurawski et al. 2001, Reda and Arafa 2002). Recently, cytochemical and immunocytochemical methods have been applied to demonstrate cholinesterase activity, and aminergic and peptidergic components of the nervous system of the gyrodactylids $M$. clarii (see El-Naggar et al. 2004), M. congolensis (see El-Naggar et al. 2007) and Gyrodactylus rysavyi (see Arafa et al. 2007) from the gills and skin of $C$. gariepinus in Egypt.
A few histochemical studies have revealed hydrolytic enzyme activity in the tissues of monogenean parasites (see for example, Smyth and Halton 1983, Buchmann et al. 1987, Siddiqui and Kulkarni 1987, Buchmann 1998). In Egypt, Abd El-Hady et al. (2012) demonstrated histochemically the activity of five enzymes, namely alkaline phosphatase (AlPase), acid phosphatase (AcPase), adenosine triphosphatase (ATPase), 5'-nucleotidase (5'-Nu) and glucose-6-phosphatase (G-6-Pase) in the organs and tissues of G. rysavyi from the gills and skin of C. gariepinus. In general, the enzymes AlPase, AcPase, ATPase, 5'-Nu and G-6-Pase have important roles in metabolism. AlPase is a hydrolase enzyme responsible for dephosphorylation (removing phosphate groups) from many types of molecules, including nucleotides, proteins, and alkaloids. Alkaline phosphatase is most effective in an alkaline environment. AcPase is a type of enzyme used to free attached phosphate groups from other molecules during digestion. It is stored in lysosomes and has an acid $\mathrm{pH}$ optimum. ATPases are a class of enzymes that catalyse the decomposition of adenosine triphosphate (ATP) into adenosine diphosphate (ADP) and a free phosphate ion which subsequently releases energy. A nucleotidase is a hydrolytic enzyme that catalyses the hydrolysis of a nucleotide. This 
process has an important function in digestion because it breaks down consumed nucleic acids. 5'-Nu is involved in various functions, such as cell-cell communication, nucleic acid repair, signal transduction and membrane transport. G-6-Pase is an enzyme that hydrolyses glucose-6phosphate, resulting in the creation of a phosphate group and free glucose.

In the present study, this work has been extended to demonstrate histochemically the activity and distribution of the same five enzymes in $M$. clarii. This will provide an opportunity to compare the distribution of these enzymes with those in other monogeneans, including other gyrodactylids parasitizing the same host fish. The present study will provide a basis for future attempts to control these potential pathogens by targeting essential parasite enzymes.

\section{MATERIALS AND METHODS}

Specimens of Clarias gariepinus were caught from the Damietta branch of the Nile River near Mansoura city, Dakahlia province, Egypt. Fishes were kept alive in an aquarium containing aerated river water. The gills were removed, placed in filtered river water and viewed with a stereomicroscope. Specimens of M. clarii were removed with the aid of fine needle.

\section{Examination of whole-mount specimens}

Dislodged parasites were transferred, with a drop of water onto a clean glass slide, gently covered with a cover slip and examined using phase-contrast and oil immersion optical equipment. Some living specimens were flattened carefully under a cover slip and preserved either in $10 \%$ formaldehyde or Bouin's fixative for about $1 \mathrm{~h}$. The parasites were then washed several times in distilled water, stained in haematoxylin and eosin, dehydrated in an ascending series of ethyl alcohol, cleared in xylene or terpineol, mounted in Canada balsam or DPX and examined using phase-contrast and bright field microscopy.

\section{Histochemical tests}

AlPase activity according to El-Aaser and Hassanein (1975) with some modifications:

Living, flattened specimens of $M$. clarii were fixed in a mixture of $95 \%$ methanol and $4 \%$ formaldehyde for about $30 \mathrm{~min}$, then washed in distilled water, incubated for $1 \mathrm{~h}$ in the following stock solution at $\mathrm{pH} 9.5: 150 \mathrm{ml}$ of $0.2 \mathrm{M}$ tris- buffer $+25 \mathrm{ml}$ of $0.05 \mathrm{M} \beta$-glycerophosphate $+50 \mathrm{ml}$ distilled water $+6 \mathrm{ml}$ of $1 \% \mathrm{~L}$-tartaric acid. The specimens were transferred to the following mixture for about $1.5 \mathrm{~h}: 45 \mathrm{ml}$ of the previous stock solution $+5 \mathrm{ml}$ of $1 \%$ lead nitrate $+0.5 \mathrm{ml}$ of $0.05 \mathrm{M}$ magnesium chloride, followed by washing in distilled water. The parasites were stained in a freshly prepared $1 \%$ solution of ammonium sulphide for 2-3 min, washed in distilled water, mounted in neutral glycerine jelly and examined using bright field microscopy.

AcPase activity according to Tice and Barnett (1962) with some modifications:

Living, flattened parasites were fixed in a mixture of $25 \mathrm{ml}$ of methanol $+20 \mathrm{ml}$ acetone $+5 \mathrm{ml}$ formaldehyde for about 45 $60 \mathrm{~min}$, and then washed in distilled water. The specimens were incubated in the following mixture: $20 \mathrm{ml}$ of $0.05 \mathrm{M}$ acetate buffer $+3 \mathrm{ml}$ of $1 \%$ lead nitrate $+2 \mathrm{ml}$ of $0.05 \mathrm{M} \beta$-glycerophosphate for about $2 \mathrm{~h}$ and then washed in distilled water. The parasites were stained in freshly prepared $1 \%$ ammonium sulphide for 2-3 min, washed in distilled water, mounted in glycerine jelly and examined using bright field microscopy.

ATPase activity according to Wachstein and Meisel (1957) with some modifications:

Living, flattened specimens were fixed in a mixture of $2.5 \%$ glutaraldehyde $(\mathrm{pH} 7.4)$ for $5-7 \mathrm{~min}$ at $4{ }^{\circ} \mathrm{C}$. They were washed with distilled water and incubated in the following mixture containing specific substrate: $2 \mathrm{ml}$ of $0.2 \mathrm{M}$ tris-maleate $\mathrm{pH} 7.4$ $+8.5 \mathrm{ml}$ distilled water $+3 \mathrm{ml}$ of $1 \%$ lead nitrate $+1 \mathrm{ml}$ of $0.1 \mathrm{M}$ magnesium chloride $+2.5 \mathrm{ml}$ of $0.05 \mathrm{M}$ adenosine-5-triphosphate disodium salt for $1 \mathrm{~h}$ at $37^{\circ} \mathrm{C}$. The specimens were then washed in distilled water and stained in freshly prepared $1 \%$ ammonium sulphide for $2-3 \mathrm{~min}$, washed in distilled water, mounted in neutral glycerine jelly and examined using bright field microscopy.

5'-Nu activity according to Wachstein and Meisel (1957) with some modifications:

Living, flattened parasites were fixed in a mixture of $2.5 \%$ glutaraldehyde ( $\mathrm{pH} 7.4$ ) for $5-7 \mathrm{~min}$ at $4{ }^{\circ} \mathrm{C}$. The specimens were washed in distilled water and incubated in the following mixture for $1 \mathrm{~h}$ at $37^{\circ} \mathrm{C}: 12 \mathrm{ml}$ of $0.2 \mathrm{M}$ of tris-maleate, $\mathrm{pH} 7.4+8.5 \mathrm{ml}$ distilled water $+3.5 \mathrm{ml}$ of $1 \%$ lead nitrate $+1 \mathrm{ml}$ of 0.1 magnesium chloride $+2.5 \mathrm{ml}$ of $0.05 \mathrm{M}$ adenosine-5'-monophosphate disodium salt. The specimens were then washed in distilled water and stained in $1 \%$ ammonium sulphide for 2-3 min. After a further washing in distilled water the specimens were mounted in neutral glycerine jelly and examined using bright field microscopy.

G-6-Pase activity according to Tice and Barnett (1962) with some modifications:

Living, flattened parasites were fixed in $2.5 \%$ glutaraldehyde (pH 7.4) for 3-4 min at $4^{\circ} \mathrm{C}$, washed in distilled water, incubated in the following mixture for $30 \mathrm{~min}$ at $37^{\circ} \mathrm{C}: 20 \mathrm{ml}$ of $0.1 \mathrm{M}$ acetate buffer at $\mathrm{pH} 6.4+3 \mathrm{ml}$ of $1 \%$ lead nitrate $+2 \mathrm{ml}$ of $0.05 \mathrm{M}$ glucose- 6 -phosphate disodium salt. After washing in distilled water the specimens were stained in freshly prepared $1 \%$ ammonium sulphide for $2-3 \mathrm{~min}$. After a further washing in distilled water, the specimens were mounted in neutral glycerine jelly and examined using bright field microscopy.

\section{RESULTS}

\section{Main anatomical features of Macrogyrodactylus clarii}

Most of the main anatomical features of $M$. clarii are shown in Fig. 1. Macrogyrodactylus clarii has an elongated body and a posterior attachment organ or haptor. Gland cells constituting the anterior adhesive apparatus are found in the anterior region of the body and open on lobes on the anterior extremity of the head region. The digestive system consists of a mouth, buccal tube, pharynx, oesophagus and two intestinal limbs. The pharynx consists of an anterior highly muscular region and a posterior mainly glandular region. The two intestinal limbs extend posteriorly and end blindly. The female reproductive system comprises an egg-cell-forming region, a receptaculum seminis and a uterus which contains up to four embryos, one inside the other. The male reproductive system 

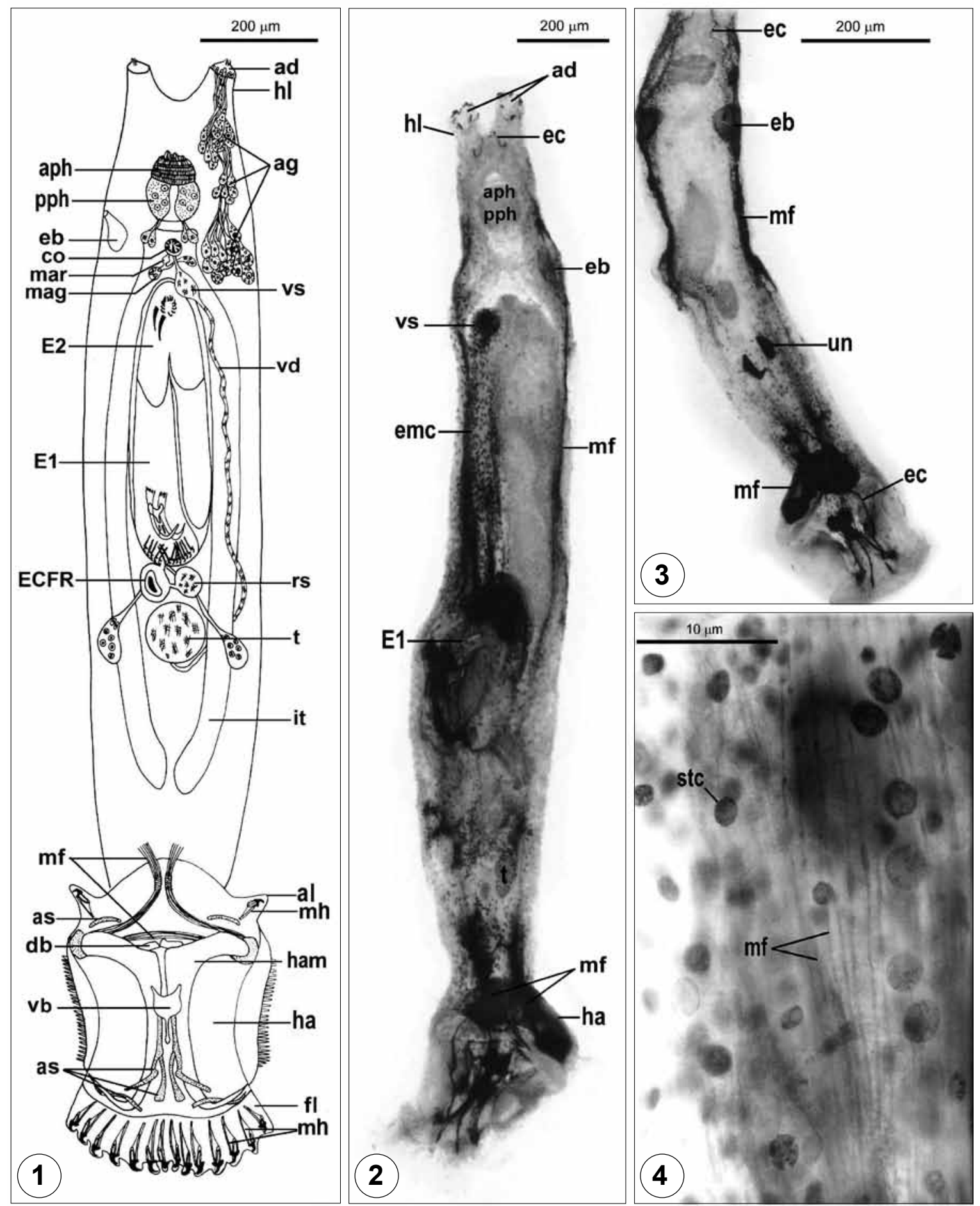

Fig. 1. Diagram showing the main anatomical features of Macrogyrodactylus clarii. Figs. 2-4. Photomicrographs of whole-mount preparations of $M$. clarii showing the positive reaction for alkaline phosphatase (AlPase). Figs. 2, 3. Whole worms. Fig. 4. Magnified part of the lateral region of body. Abbreviations: ad - adhesive area; ag - adhesive glands; al - anterolateral lobe of the haptor; aph - anterior region of the pharynx; as - accessory sclerites; co - copulatory organ; db - dorsal bar; E1 - first embryo; E2 - second embryo; eb - excretory bladder; ec - excretory canal; ECFR - egg-cell-forming region; emc - embryonic cells; fl - flap; ha - haptor; ham - hamulus; hl - head lobe; it - intestine; mag - male accessory gland; mar - male accessory reservoir; mf - muscle fibres; $\mathrm{mh}$ - marginal hooklets; pph - posterior region of the pharynx; rs - receptaculum seminis; stc - subtegumental cells; $t$ - testis; un - unidentified mass of cells; vb - ventral bar; vd - vas deferens; vs - vesicula seminalis. Fig. 1 reproduced with permission from Arafa et al. (2009). 
comprises a single testis, vas deferens, two male accessory glands, one male accessory reservoir and a copulatory organ. The haptor possesses one pair of hamuli, two bars (one dorsal and one ventral), accessory sclerites and eight pairs of marginal hooklets. Fourteen marginal hooklets are found within a flap projecting from the dorsal surface of the posterior region of the haptor. Two anterolateral lobes found one on each anterolateral region of the haptor accommodate the other two marginal hooklets. The excretory system consists of many flame cells, two excretory bladders and two excretory canals.

\section{Histochemical enzyme activities in Macrogyrodactylus clarii}

In the present study, histochemical methods were applied to whole-mount preparations to determine the distribution of five enzymes, namely alkaline phosphatase (AlPase), acid phosphatase (AcPase), adenosine triphosphatase (ATPase), 5'-nucleotidase ( $\left.5^{\prime}-\mathrm{Nu}\right)$, and glucose6-phosphatase (G-6-Pase). The following organs and tissues were studied: the head region, anterior adhesive glands, mouth region, pharynx, intestine, testis, vesicula seminalis, male accessory gland, male accessory reservoir, copulatory organ, receptaculum seminis, egg-cellforming region, embryonic cells, excretory system, nerve cells, haptor, muscle fibres and subtegumental cell bodies (cytons).

AlPase activity. In M. clarii, AlPase activity was not detected in the head region, head lobes and anterior adhesive glands, but was detected in the anterior adhesive areas at the distal extremities of the head lobes (Fig. 2). No positive reaction for AlPase was revealed in the digestive system. In the male reproductive system, a positive reaction for AlPase was detected in the testis and vesicula seminalis, while in the female reproductive system a strong positive reaction for AlPase was detected in the receptaculum seminis and in the embryonic cells in the uterus (Fig. 2). An interesting feature is the great number of positively stained cells detected close to the wall of the uterus. Strong positive reactions were also found in the excretory bladders, excretory canals, nerve cells, haptor, muscle fibres and subtegumental cell bodies (Figs. 2-4). In the prehaptoral region, two unknown positively stained structures were detected (Fig. 3).

AcPase activity. A positive reaction for AcPase was observed in the head lobe region and anterior adhesive area (Fig. 5). A strong positive reaction was also observed in the intestine (Fig. 5). Organs of the male reproductive system, namely testis (Fig. 6), vesicula seminalis and male accessory glands, were positively stained. Although no positive reaction for AcPase was detected in the organs of the female reproductive system, a positive reaction was detected in the embryonic cells inside the uterus (Fig. 5).
The excretory bladders, excretory canals of the adult and embryo, and flame cells showed a strong positive reaction for AcPase (Figs. 5-8). A positive reaction was also recognised in the nerve cord (Fig. 9), nerve cells (Figs. 8-10), haptor (Fig. 7), subtegumental cell bodies (Fig. 7) and muscle fibres (Figs. 7, 8). The unknown structures in the prehaptoral region, which stained positively for AlPase (see above), were also positively stained for AcPase (Fig. 7). At high power, a nerve cell showed a negatively stained nucleus, positively stained cytoplasm and positively stained granules in the cytoplasm (Fig. 10).

ATPase activity. A strong positive reaction for ATPase was observed in the intestine (Figs. 11, 12), excretory bladders (Fig. 11) and excretory canals. Some cells and granules in the intestinal lumen were also positively stained (Fig. 12). ATPase activity was restricted to the digestive and excretory systems.

5'-Nu activity. Positive reactions for $5^{\prime}-\mathrm{Nu}$ were restricted to a few organs and tissues, namely the intestine, excretory bladders, excretory canals and muscle fibres in the adult worm, as well as the first embryo (Fig. 13).

G-6-Pase activity. Like ATPase and 5'-Nu, a positive reaction for G-6-Pase was observed in a few organs, namely the intestine, excretory bladders and excretory canals of the adult parasite, some nerve cells (Figs. 14, 15) and the first embryo.

Summary. The histochemical reactions of AlPase, AcPase, ATPase, 5'-Nu and G-6-Pase in the organs and tissues of M. clarii are presented in Table 1 .

\section{DISCUSSION}

Although many authors have used histochemical methods to localise enzymes in platyhelminths (e.g., Farooq and Farooqi 1984, Delcacho et al. 1996, Humiczewska 2002, Vatankhah et al. 2003), there have been few studies on monogeneans. Most of these have revealed the occurrence of AlPase, AcPase (for example, Lyons 1970, Buchmann et al. 1987, Buchmann 1988, 1998). In the present work, histochemical techniques were applied, for the first time, to study the distribution of the enzymes AlPase, AcPase, ATPase, 5'-Nu and G-6-Pase in the gyrodactylid monogenean Macrogyrodactylus clarii. These enzymes showed marked differences in distribution and activity in the organs and tissues of $M$. clarii, some enzymes being widespread while others were restricted to particular organs or tissues. An interesting finding is the difference in the distribution of these enzymes in $M$. clarii and in Macrogyrodactylus congolensis (unpublished data), the former inhabiting the gills and the latter inhabiting the skin of the same host fish, Clarias gariepinus.

Except for a positive reaction for AcPase in the adhesive areas of $M$. clarii, the enzymes showed no activity 

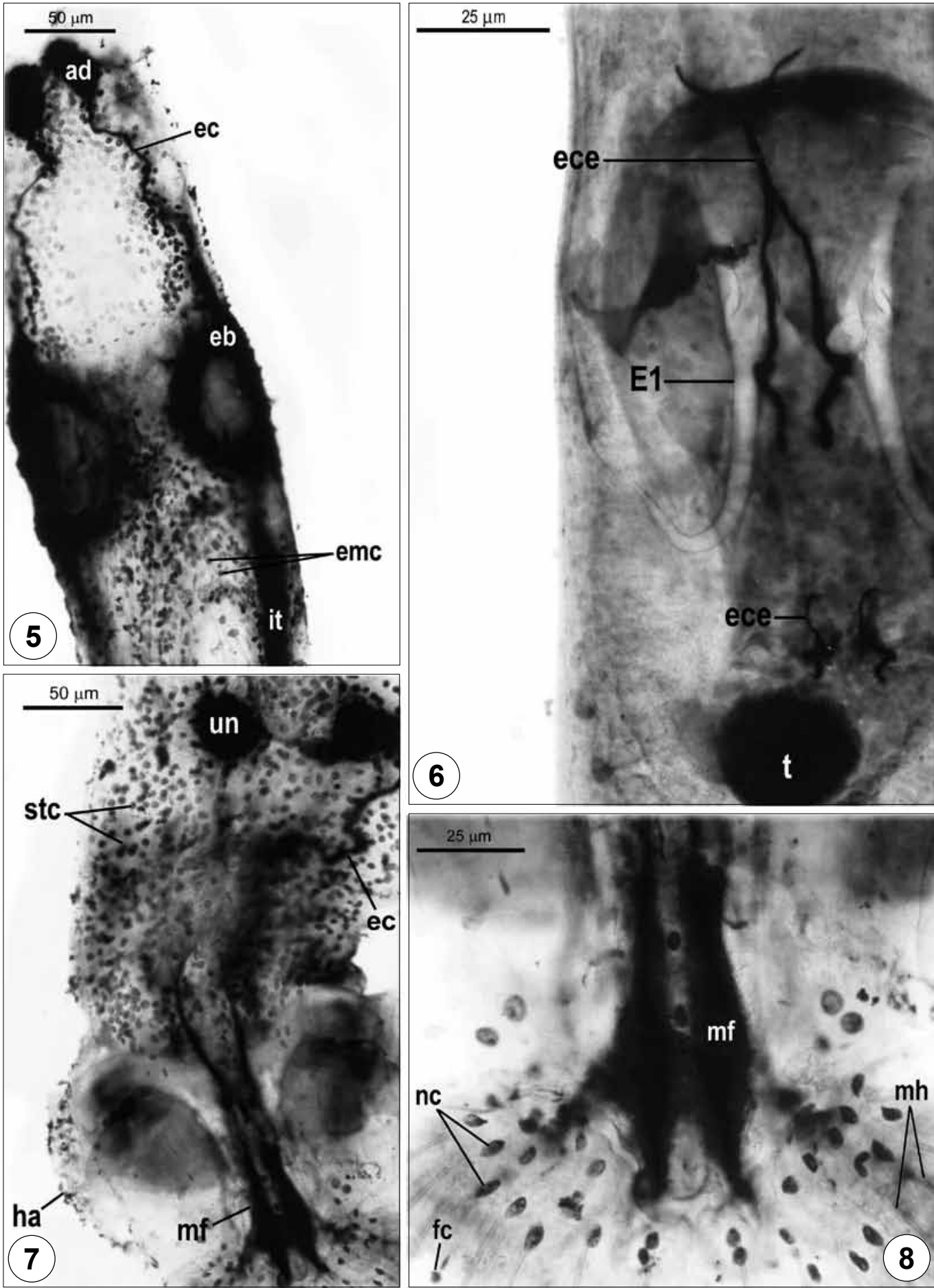

Figs. 5-8. Photomicrographs of a whole-mount preparation of Macrogyrodactylus clarii showing the positive reaction for acid phosphatase (AcPase). Fig. 5. Anterior region of the body; adhesive area (ad), excretory bladders (eb), excretory canals (ec), embryonic cells (emc) and intestine (it). Fig. 6. Excretory canals (ece) in the anterior region and haptor of the first embryo (E1); $t$ - testis. Fig. 7. Posterior region of the body; excretory canal (ec), haptor (ha), muscle fibres (mf), subtegumental cells (stc) and unidentified mass of cells (un). Fig. 8. Posterior region of the haptor; flame cell (fc), muscle fibres (mf), marginal hooklet (mh) and nerve cells (nc). 

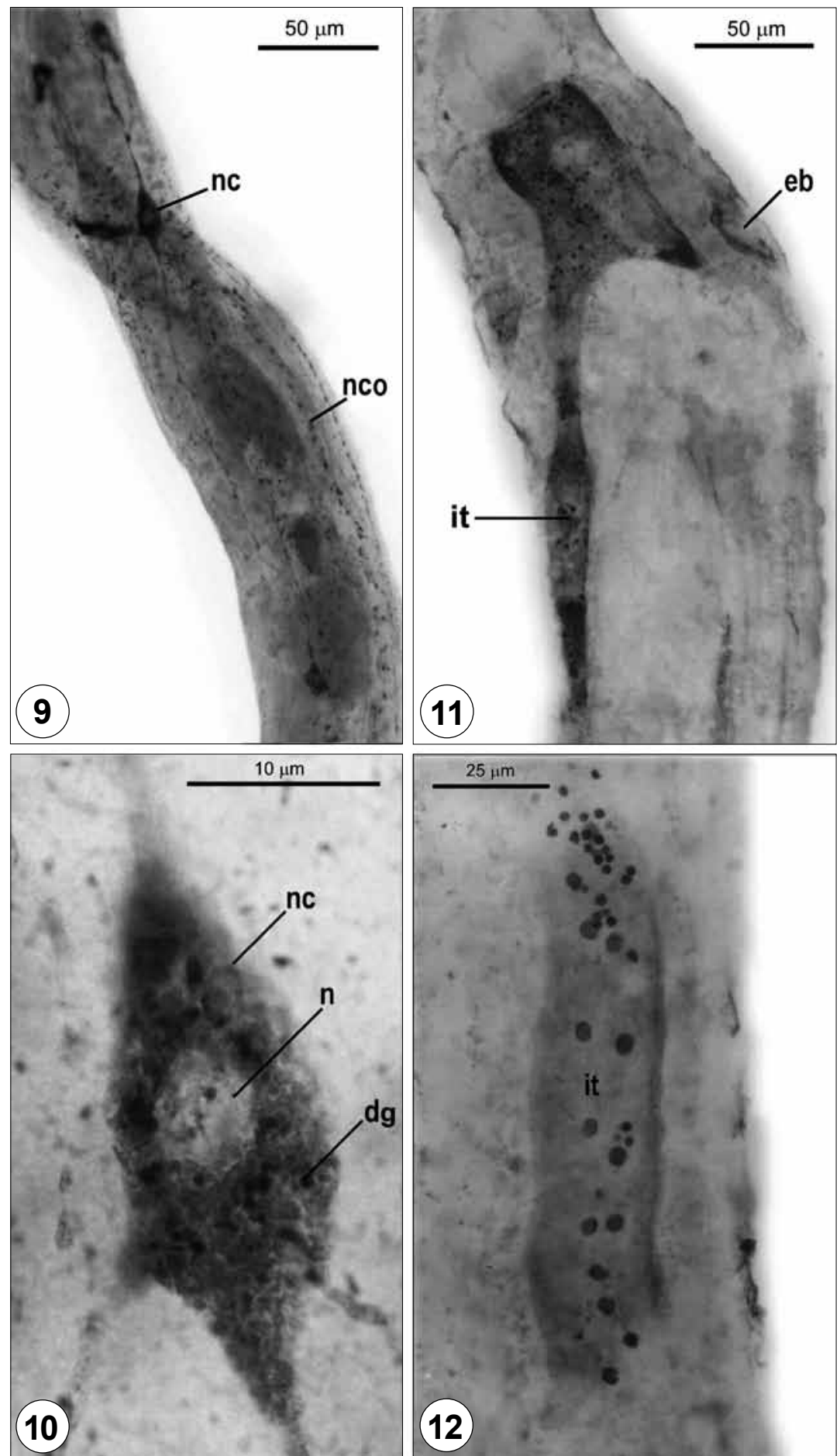

Figs. 9-12. Photomicrographs of whole-mount preparations of Macrogyrodactylus clarii showing the positive reaction for acid phosphatase (AcPase) (Figs. 9, 10) and adenosine triphosphatase (ATPase) (Figs. 11, 12). Fig. 9. Middle region of the body; nerve cells (nc) and nerve cords (nco). Fig. 10. Magnified nerve cell (nc) with densely stained granules (dg) and negatively stained nucleus (n). Fig. 11. Middle region of the body; excretory bladder (eb) and intestine (it). Fig. 12. A magnified sector of the intestine (it). 


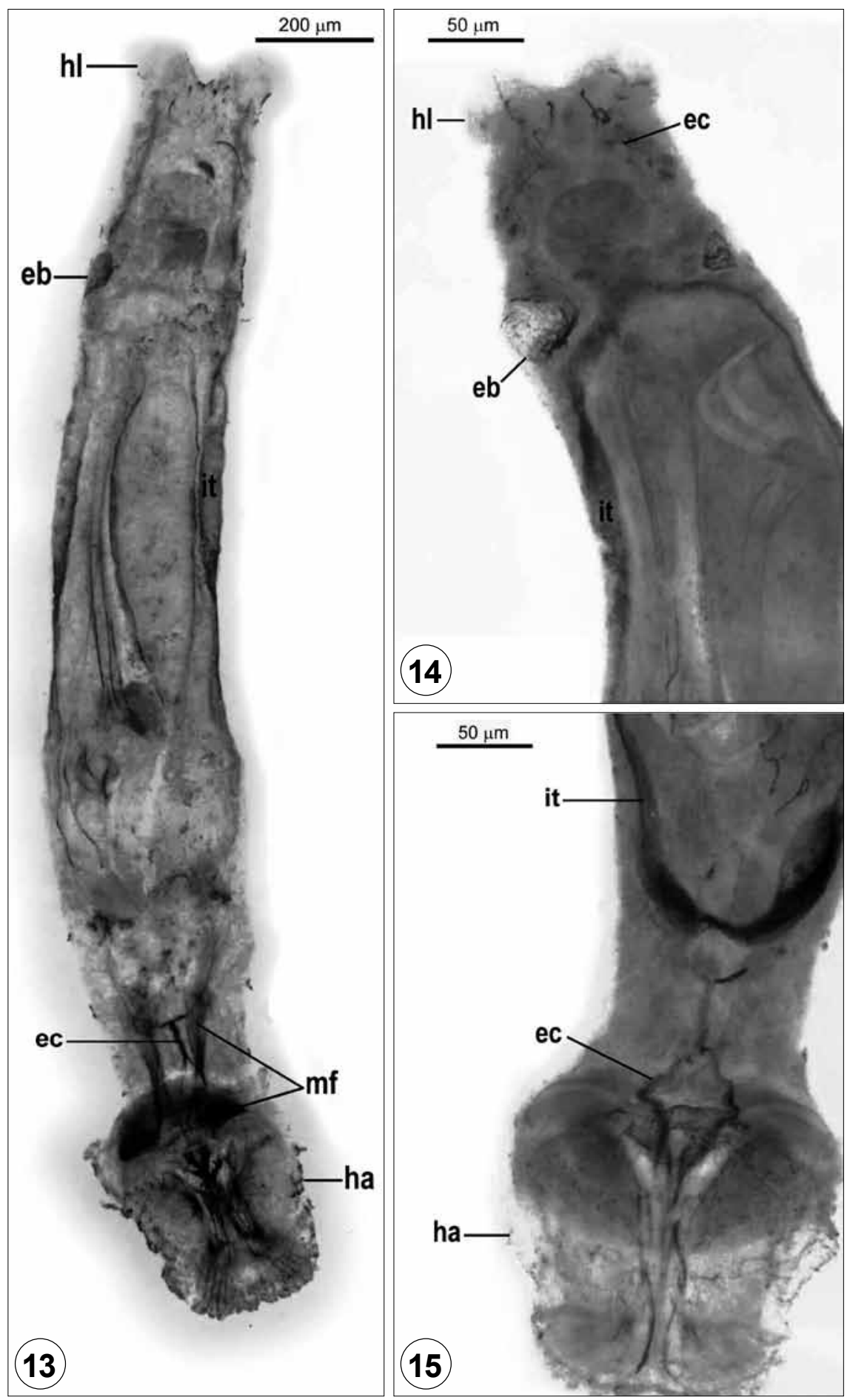

Figs. 13-15. Photomicrographs of whole-mount preparations of Macrogyrodactylus clarii stained for 5'-nucleotidase (5'-Nu) (Fig. 13) and glucose-6-phosphatase (G-6-Pase) (Figs. 14, 15). Fig. 13. Excretory bladder (eb), excretory canal (ec), haptor (ha), head lobe (hl), intestine (it) and muscle fibres (mf). Fig. 14. Anterior region of the body; excretory bladder (eb), excretory canal (ec), head lobe (hl) and intestine (it). Fig. 15. Posterior region of the body showing prehaptoral region and haptor (ha); ec - excretory canals; it - intestine. 
Table 1. Histochemical reactions of alkaline phosphatase (AlPase), acid phosphatase (AcPase), adenosine triphosphatase (ATPase), 5'-nucleotidase (5'-Nu) and glucose-6-phosphatase (G-6-Pase) in different organs and tissues of Macrogyrodactylus clarii. Positive reaction $(+)$, negative reaction $(-)$.

\begin{tabular}{lccccc}
\hline Organs and tissues & \multicolumn{3}{c}{ AlPase AcPase ATPase 5'-Nu G-6-Pase } \\
\hline Head lobes & - & + & - & - & - \\
Anterior adhesive glands & - & - & - & - & - \\
Mouth & - & - & - & - & - \\
Pharynx & - & - & - & - & - \\
Intestine & - & + & + & + & + \\
Testis & + & + & - & - & - \\
Vesicula seminalis & + & + & - & - & - \\
Male accessory gland & - & + & - & - & - \\
Male accessory reservoir & - & - & - & - & - \\
Copulatory organ & - & - & - & - & - \\
Receptaculum seminis & + & - & - & - & - \\
Egg-cell-forming region & - & - & - & - & - \\
Embryonic cells & + & + & - & - & - \\
Excretory system & + & + & + & + & + \\
Nerve cells & + & + & - & - & + \\
Haptor & + & + & - & + & - \\
Muscle fibres & + & + & - & + & - \\
Subtegumental cell bodies & + & + & - & - & - \\
(cytons) & & & & & \\
\hline
\end{tabular}

in the gland cells of the anterior adhesive apparatus. Two enzymes, namely 5'-nu and G-6-Pase, exhibited marked activity in the anterior adhesive glands of $M$. congolensis (unpublished data). No enzyme activities were observed in the anterior adhesive glands of Gyrodactylus rysavyi (see Abd El-Hady et al. 2012). Because of the absence of AlPase activity from the tissues of the monogenean Pseudodactylogyrus anguillae, Buchmann et al. (1987) suggested that the anterior adhesive apparatus has no histolytic function during feeding. However, Llewellyn (1960) suggested that the glands of the anterior adhesive apparatus may have a histolytic function during feeding in amphibdellid monogeneans. Absence of all the studied enzymes from the anterior adhesive glands of $M$. clarii indicates that the glands of the anterior adhesive apparatus may have no histolytic function during feeding.

AlPase and AcPase activities were detected in many organs and tissues of $M$. clarii. The same finding was recorded in G. rysavyi (see Abd El-Hady et al. 2012). Previously, strong activity of AcPase has not been detected in monogeneans (Halton 1967, Smyth and Halton 1983). However, AlPase has been frequently reported in monogeneans (for example, Halton 1967, Buchmann 1988, 1998). A few studies have actually stated that it can occur in platyhelminths (Lyons 1970, Buchmann et al. 1987, Buchmann 1988, 1998). Delcacho et al. (1996) suggested that AlPase has an important role in phosphate turnover in the fertile hydatid cysts of Echinococcus granulosus and may also regulate calcium metabolism.
At the transmission electron microscopy (TEM) level, El-Naggar and Cable (2007) detected four kinds of secretory subtegumental cell bodies (cytons) in M. clarii. In the present study, AlPase and AcPase were demonstrated in these cell bodies. In addition to AlPase and AcPase, ATPase was also detected in the subtegumental cell bodies of G. rysavyi (see Abd El-Hady et al. 2012). At the TEM level, AcPase was detected within tegumentary folds and in lysosomes in the subtegumentary cell bodies of the redia of Cryptocotyle lingua (see Krupa et al. 1968). AlPase, AcPase and 5'-nu were detected in the sporocyst of Fasciola hepatica (see Humiczewska 2002). Humiczewska suggested that the high activity of these three enzymes indicates that they play a significant role in the metabolism of the sporocyst. Smyth and Halton (1983) reported that AlPase, ATPase and 5'-nu are commonly associated with membrane transport and their role lies mostly in the active transport of nutrients and metabolites through cell membranes. In the present investigation, the occurrence of most enzymes in the intestine, subtegumental cell bodies, embryonic cells, excretory system, testis and muscle fibres indicates that these body regions are active sites for active transport of nutrients and metabolites.

Except for AlPase, all the studied enzymes showed marked activity in the digestive system of M. clarii. AlPase, AcPase, ATPase, 5'-Nu and G-6-Pase were recorded in G. rysavyi (see Abd El-Hady et al. 2012). The anterior muscular region of the pharynx of $M$. clarii and $M$. congolensis accommodates papillae which were seen protruding from the mouth opening (El-Naggar and Serag 1987, El-Naggar et al. 1999). Hydrolytic enzymes may be released from the pharynx onto the host's epidermis and start extracorporeal digestion. Arafa (1999) found partially digested food in the intestine of the skin parasite $M$. congolensis and found evidence indicating that digestion of food was completed in the gastrodermis. Thereafter, the completely digested food was transported via the gastrodermis to the neighbouring tissues. Enzymes from the pharynx may also help in the partial digestion of food inside the intestinal lumen and its final digestion in the gastrodermis. Extracorporeal digestion is likely to occur in other monogeneans, for example Entobdella soleae (see Kearn 1963). A localised reaction to the release of pharyngeal digestive enzymes onto host skin may follow (see Richards and Chubb 1996, Buchmann and Bresciani 1998). Such a reaction may also be induced by mechanical injury as a result of insertion of hooklets (see Cone and Odense 1984, Buchmann and Bresciani 1997). The commonly observed changes of parasite location on the host (Harris 1988, Buchmann and Uldal 1997) could also be induced by such local host reactions.

In the present study, embryonic cells of $M$. clarii showed positive reactivity for AlPase and AcPase. In G. rysavyi, Abd El-Hady et al. (2012) recorded AlPase, 
AcPase and ATPase in the embryonic cells. This finding indicates intensive phosphorylation processes inside the uterus. Such processes seem likely to facilitate and accelerate cell division at early stages and the development of nested embryos within the same uterus.

In the present study, ATPase, 5'-nu and G-6-Pase activity was restricted to a few organs, particularly the intestine and excretory system. A similar finding was observed in G. rysavyi (see Abd El-Hady et al. 2012). However, in M. congolensis, ATPase, 5'-nu and G-6-Pase activity was detected in most of the organs examined (unpublished data). The present findings indicate that protein synthesis in M. clarii and G. rysavyi is less than in M. congolensis. This may be a reflection of the difference in body size be- tween the three monogeneans, $M$. congolensis being larger than M. clarii and G. rysavyi. 5'-nu is associated with the breakdown and transportation of nucleic acid (Humiczewska 2002). This enzyme belongs to the plasmalemma hydrolases, the function of which is to facilitate membrane penetration by nucleotides and polynucleotides. Uusitalo and Karnovsky (1977) showed that 5'-nu plays an important role in the migration of cells, as it might be implicated in the production of adenosine, while Uusitalo (1981) proposed that the enzyme plays a role in intercellular regulatory mechanisms, possibly by producing nucleosides that may in turn affect cyclic nucleotide levels. According to Schubert et al. (1979), 5'-nu may participate in the process of neurotransmission.

\section{REFERENCES}

Abd El-Hady E.K., Arafa S.Z., El-Naggar M.M., El-AbBASSY S.A. 2012: Demonstration of alkaline phosphatase, acid phosphatase, adenosine triphosphatase, 5'-nucleotidase and glucose-6-phosphatase activities in the monogenean parasite Gyrodactylus rysavyi. Egypt. J. Zool. (In press.)

Arafa S.Z. 1999: Biological studies on some monogenean parasites of the teleost Clarias gariepinus in Dakahlia province. Ph.D. thesis, Zoology Department, Faculty of Sciences, Mansoura University, Mansoura, Egypt, 350 pp.

Arafa S.Z., El-Naggar M.M., El-Abbassy S.A. 2009: Mode of attachment and histopathological effects of Macrogyrodactylus clarii, a monogenean gill parasite of the catfish Clarias gariepinus, with a report on host response. Acta Parasitol. 54: 103-112.

Arafa S.Z., El-Naggar M.M., El-Abbassy S.A., Stewart M.T., Halton D.W. 2007: Neuromusculature of Gyrodactylus rysavyi, a monogenean gill and skin parasite of the catfish Clarias gariepinus. Parasitol. Int. 56: 297-307.

Buchmann K. 1988: Feeding of Pseudodactylogyrus bini (Monogenea) from Anguilla anguilla. Bull. Eur. Assoc. Fish Pathol. 8: 79-81.

Buchmann K. 1998: Histochemical characteristics of Gyrodactylus derjavini parasitizing the fins of rainbow trout (Oncorhynchus mykiss). Folia Parasitol. 45: 312-318.

Buchmann K., Bresciani J. 1997: Parasitic infections in pond reared rainbow trout Oncorhynchus mykiss in Denmark. Dis. Aquat. Org. 28: 125-138.

Buchmann K., Bresciani J. 1998: Microenvironment of Gyrodactylus derjavini on rainbow trout Oncorhynchus mykiss: association between mucous cell density in skin and site selection. Parasitol. Res. 84: 17-24.

Buchmann K., Køie M., Prentø P. 1987: The nutrition of the gill parasitic monogenean Pseudodactylogyrus anguillae. Parasitol. Res. 73: 532-537.

Buchmann K., Mellergaard S. 1988: Histochemical demonstration of the inhibitory effect of Nuvan and Neguvon on cholinesterase activity in Pseudodactylogyrus anguillae (Monogenea). Acta Vet. Scand. 29: 51-55.

Buchmann K., Uldal A. 1997: Gyrodactylus derjavini infections in four salmonids: comparative host susceptibility and site selection of parasites. Dis. Aquat. Org. 28: 201-209.

Cable J., Marks N.J., Halton D.W., Shaw C., Johnston C.F., Tinsley R.C., Gannicott A.M. 1996: Cholinergic, serotonin- ergic and peptidergic components of the nervous system of Discocotyle sagittata (Monogenea: Polyopisthocotylea). Int. J. Parasitol. 26: 1357-1367.

Cone D.K., Odense P.H. 1984: Pathology of five species of $G y$ rodactylus Nordmann, 1832 (Monogenea). Can. J. Zool. 62: 1084-1088.

Delcacho E., Causape C., Sanchez-Acedo C., Quilez J. 1996: Cytochemical study of germinal membrane of Echinococcus granulosus cyst. Vet. Parasitol. 62: 101-106.

El-Aaser A.A., Hassanein S.M. 1975: A new direct lead technique for histochemical demonstration of alkaline phosphatase activity. Acta Biol. Acad. Sci. Hung. 26: 105-110.

El-AbBassy S.A. 2001: Biological and histochemical studies on some monogenean parasites of the catfish Clarias gariepinus inhabiting Nile Delta waters. M.Sc. Thesis, Zoology Department, Faculty of Science, Mansoura University, Egypt, 150 pp.

El-Naggar M.M. 1993: Scanning electron microscope observations on the head lobes and haptor of the monogenean Macrogyrodactylus clarii Gussev, 1961. J. Egypt. Ger. Soc. Zool. 10: 143-155.

El-Naggar M.M., Arafa S.Z., El-Abbassy S.A., Kearn G.C. 2001a: Chaetotaxy of the monogeneans Macrogyrodactylus clarii and $M$. congolensis from the gills and skin of the catfish Clarias gariepinus in Egypt, with a note on argentophilic elements in the nervous system. Folia Parasitol. 48: 201-208.

El-Naggar M.M., Arafa S.Z., El-Abbassy S.A., Stewart M.T., Halton D.W. 2007: Neuromusculature of Macrogyrodactylus congolensis, a monogenean skin parasite of the Nile catfish Clarias gariepinus. Parasitol. Res. 100: 265-279.

El-Naggar M.M., Arafa S.Z., Stewart M.T., El-Abbassy S.A., Halton D.W. 2004: Neuromusculature of Macrogyrodactylus clarii, a monogenean gill parasite of the Nile catfish Clarias gariepinus in Egypt. Parasitol. Res. 94: 163-175.

El-Naggar M.M., Cable J. 2007: Ultrastructural observations on the elusive subtegumental cells of the viviparous gill monogenean, Macrogyrodactylus clarii. Parasitol. Res. 101: 9-17.

El-Naggar M.M., El-Naggar A.M., El-Abbassy S.A. 2001b: Microhabitat and movement of the viviparous monogeneans Gyrodactylus alberti, Macrogyrodactylus clarii and M. congolensis from the Nile catfish Clarias gariepinus. J. Egypt. Ger. Soc. Zool. 35: 169-187.

El-Naggar M.M., Kearn G.C., Hagras A.E., Arafa S.Z. 1999: On some anatomical features of Macrogyrodactylus congolen- 
sis, a viviparous monogenean ectoparasite of the catfish Clarias gariepinus from Nile water. J. Egypt. Ger. Soc. Zool. 29: 1-24.

El-Naggar M.M., Serag H.M. 1987: Redescription of Macrogyrodactylus clarii Gussev 1961, a monogenean gill parasite of Clarias lazera in Egypt. Arab Gulf J. Sci. Res., Agric. Biol. Sci. 5: 257-271.

Faroog R., Faroogi U.K. 1984: Histochemical localization of phosphomonoesterases in Avitellina lahorea Woodland, 1927 (Cestoda: Anoplocephalida). J. Helminthol. 58: 169-173.

Hagras A.E., El-Naggar M.M., Kearn G.C., Arafa S.Z. 1999: Monthly occurrence, seasonal population dynamics and distribution of four monogeneans on the catfish Clarias gariepinus in Dakahlia province, lower Egypt. J. Egypt. Ger. Soc. Zool. 29: 49-66.

Halton D.W. 1967: Studies on phosphatase activity in Trematoda. J. Parasitol. 53: 46-54.

Halton D.W., Jennings J.B. 1964: Demonstration of the nervous system of the monogenetic trematode Diplozoon paradoxum Nordmann by the indoxyl acetate method for esterases. Nature 202: 510-511.

Halton D.W., Morris G.P. 1969: Occurrence of cholinesterase and ciliated sensory structures in a fish gill fluke, Diclidophora merlangi (Trematoda: Monogenea). Z. Parasitenkd. 33: 21-30.

HARRIS P.D. 1988: Changes in the site specificity of Gyrodactylus turnbulli Harris, 1986 (Monogenea) during infections of individual guppies (Poecilia reticulata Peters, 1859). Can. J. Zool. 66: 2854-2857.

Humiczewska M. 2002: Some specific and non-specific phosphatases of the sporocyst of Fasciola hepatica. II. Enzymes associated with the membrane transport. Folia Parasitol. 49: 221-226.

Kearn G.C. 1963: Feeding in some monogenean skin parasites: Entobdella solea on Solae solae and Acanthocotyle sp. on Raia clavata. J. Mar. Biol. Ass. UK 43: 749-766.

Krupa P.L., Cousineau G.H., Bal A.K. 1968: Ultrastructural and histochemical observations on the body wall of Cryptocotyle lingua rediae (Trematoda). J. Parasitol. 54: 900-908.

Llewellyn J. 1960: Amphibdellid (monogenean) parasites of electric rays (Torpedinidae). J. Mar. Biol. Assoc. UK 39: 561-589.

Lyons K.M. 1970: The fine structure and function of the adult epidermis of two skin parasitic monogeneans, Entobdella soleae and Acanthocotyle elegans. Parasitology 60: 39-52.
RAHEMO Z.I.F., GoRGEES N.S. 1987: Studies on the nervous system of Polystoma integerrimum as revealed by acetylthiocholine activity. Parasitol. Res. 73: 234-239.

Reda E.S., Arafa S.Z. 2002: Cholinergic components of the nervous system of the monogenean gill parasites, Pseudodactylogyrus bini and $P$. anguillae from the eel Anguilla anguilla in Nile Delta waters. Egypt. J. Zool. 38: 41-54.

Richards G.R., Chubb J.C. 1996: Host response to initial and challenge infections, following treatment, of Gyrodactylus bullatarudis and G. turnbulli (Monogenea) on the guppy (Poecilia reticulata). Parasitol. Res. 82: 242-247.

Schubert P., Komp W., Kreutzberg G.W. 1979: Correlation of 5 '-nucleotidase activity and selective transneuronal transfer of adenosine in the hippocampus. Brain Res. 168: 419-424.

Siddiqui A.A., KulKarni T. 1987: Histochemical distribution of phosphatases in the tissue of Mizellus indicus Jain (1957), (Monogenea: Monopisthocotylea). Riv. Parassitol. 4: 197-200.

Smyth J.D., Halton D.W. 1983: The Physiology of Trematodes (2nd Edition). Cambridige University Press, New York, xiii + $446 \mathrm{pp}$.

Tice L., BARnetT R. 1962: Fine structural localization of G-6-pase in rat liver. J. Histochem. Cytochem. 10: 754.

Uusitalo R.J. 1981: 5'-Nucleotidase activity in lymphocytes. Histochem. J. 13: 525-534.

Uusitalo R.J., Karnovsky M.J. 1977: Surface localization of 5'-nucleotidase on the mouse lymphocyte. J. Histochem. Cytochem. 25: 87-96.

Vatankhah A., Assma M., Vatankhah G.R., Shokrgoza M.A. 2003: Immunochemical characterization of alkaline phosphatase from the fluid of sterile and fertile Echinococcus granulosus cysts. Parasitol. Res. 90: 372-376.

Wachstein M., Meisel E. 1957: A comparative study of enzymatic staining reactions in the rat kidney with necrobiosis induced by ischemia and nephrotoxic agents (Mercuhydrin and DL-Serine). J. Histochem. Cytochem. 5: 204-220.

Zurawski T.H., Mousley A., Mair G.R., Brennan G.P., Maule A.G., Gelnar M., Halton D.W. 2001: Immunomicroscopical observations on the nervous system of adult Eudiplozoon nipponicum (Monogenea: Diplozoidae). Int. J. Parasitol. 31: 783-793.

Accepted 8 November 2011 